\title{
The Social Ecology of Cervical Cancer: The Challenges to Pap Smear Screening
}

\author{
Annekathryn Goodman \\ Department of Obstetrics and Gynecology, Massachusetts General Hospital, Boston, USA. \\ Email: agoodman@partners.org
}

Received October $13^{\text {th }}, 2013$; revised November $12^{\text {th }}, 2013$; accepted December $10^{\text {th }}, 2013$

Copyright (C) 2013 Annekathryn Goodman. This is an open access article distributed under the Creative Commons Attribution License, which permits unrestricted use, distribution, and reproduction in any medium, provided the original work is properly cited. In accordance of the Creative Commons Attribution License all Copyrights (c) 2013 are reserved for SCIRP and the owner of the intellectual property Annekathryn Goodman. All Copyright (C) 2013 are guarded by law and by SCIRP as a guardian.

\begin{abstract}
Cervical cancer is a preventable disease. The risk factors for the development of cervical cancer include both biologic factors and social factors. In the United States, the leading risk factor for the development of cervical cancer is not having a Pap smear for five years prior to the diagnosis of cancer. In low and middle income countries, cervical cancer incidence and mortality are directly related to the lack of both screening programs and cancer treatment facilities. This paper examines the social ecology of cervical cancer. The literature is reviewed on social and cultural barriers to access to health care and its effect of cervical cancer rates and outcomes.
\end{abstract}

Keywords: Cervical Cancer; Pap Smear; Screening; Social Ecology

\section{Introduction}

Cervical cancer is a preventable cancer. It has a long preinvasive phase that can be easily detected by an accurate screening test, the Pap smear. Pap smear screening has become so successful that the American Society of Cytologists and Cervical Pathologists (ASCCP) 2012 guidelines recommend a reduction in screening frequency to every three years [1]. Despite this highly successful test along with the use of HPV testing, which increases the screening sensitivity, women still present cervical cancer in high-income countries (HICs) such as the United States and the European Union [2].

In low and middle income countries (LMICs), screening programs with Pap smear screening are challenged by a lack of medical infrastructure. As a result, low cost solutions using visual inspection with acetic acid (VIA) have become a successful triage program for cervical disease since the mid 1990's.

Yet in LMICs, cervical cancer is the leading cause of cancer death in women. In HICs, cervical cancer is directly related to not getting a Pap smear and to not coming in for a pelvic examination. The reasons for not accessing screening opportunities whether by VIA in LMICs or by Pap smear and HPV testing in HICs is complex and nuanced by socioeconomic status, culture, and the structural violence of healthcare bureaucracies. This paper examines the social challenges to women in North America that delay or prevent a life saving, inexpensive screening test. The problem is examined at five different levels: intrapersonal, interpersonal, organizational, community and societal which are also summarized in Table 1. The paper concludes with a brief summary of the international literature.

\section{The Magnitude of the Public Health Issue}

In the United States, there were 12,610 new cases of cervical cancer and 4290 deaths in 2011. Two thirds of cervical cancer cases occur in the underserved populations of the United States including those living in rural communities and the poor [3]. In particular, the rates of cervical cancer among Latina women and African American women were 14.7 per 100,000 and 13 per 100,000 respectively compared to 8.6 per 100,000 for white women [4].

\subsection{Factors Related to Delay of Screening at the Intrapersonal Level}

The factors that impact health from an intrapersonal level include both psychological and biological issues. These 
Table 1. Challenges to Pap smear screening the social ecology levels.

\begin{tabular}{ccc}
\hline & General Influences & Barriers to Cervical Cancer Screening \\
\hline Intrapersonal level & Personality & Depression, anxiety \\
& Comprehension & Ability to navigate healthcare system \\
Less common high-risk subtype HPV
\end{tabular}

include factors that make up personality, ability to understand health issues, ability to navigate the healthcare system, and genetics.

Women who suffer from psychiatric disorders will be less likely to undergo cancer screening [5]. The consequences include delay in diagnosis and treatment. However one study demonstrated that depression and anxiety correlated with a reduction in cervical cancer screening and diagnostic delays of abnormal Pap smears [5]. Another systematic review of nineteen studies on mental illness and screening confirmed the presence of disparities in screening rates for this vulnerable population [6].

A fascinating study analyzed the distribution of HPV oncogenic subtype by ethnicity and poverty. There was a significantly lower proportion of preinvasive disease related to the most common HPV subtypes (HPV 16 and 18) among African American and Hispanic women in poverty based areas [7]. This suggests that for poor, minority women, the current 16/18 HPV vaccine may not be effective for prevention of cervical cancer.

\subsection{Screening Barriers at the Interpersonal Level}

In the social ecology health model, the interpersonal level includes the influences of the family, the home environment, and the culture and mores of the peer group. Despite universal healthcare and an aggressive cervical cancer-screening program in Canada, Chinese-Canadian women have had a higher incidence of cervical cancer and a higher death rate [8]. An analysis of Chinese women who live in North America revealed a reluctance to undergo Pap smear screening because of embarrassment. These women considered Pap smear testing to be linked to sexual promiscuity [9].

In the United States, Latinas have an increased rate of cervical cancer compared to white women. Cultural norms are important to understand. Latina women who never underwent Pap smear screening frequently held fatalistic beliefs [4]. A program of planned behavior training to increase perceived behavior control was useful to increase Pap smear screening in this population [10].

In Canada, there has been an increase in cervical cancer rates among the First Nation population. An analysis of lifestyle risk factors and screening shows no difference in Pap screening suggesting that the increase is due to an interpersonal ecology level shift dues to smoking [11].

An analysis of attitudes towards screening and compliance with Pap smear screening did not show a change based on a family history of cervical cancer [12].

\subsection{Challenges at the Organizational Level}

The organizational level of social ecology includes healthcare barriers that can occur through employment challenges, the school environment, and healthcare in- 
surance. In the absence of universal healthcare in the United States, insurance coverage becomes one of the factors associated with delays in screening for cervical cancer. Screening was strongly associated with health insurance among African American women in South Eastern United States [12].

In an analysis of the New Jersey State Cancer Registry, lack of health insurance was linked to significantly higher death rates from cancer compared people with private insurance [13]. Cervical cancer five-year survival rates for the 2002 to 2004 period were 68\% versus 73\% for uninsured versus privately insured [13]. A national health interview survey of cancer survivors analyzed the rates of screening for other cancers compared to healthy controls. Women who had survived one cancer were less likely to undergo cervical cancer screening compared to the general population and were between $8 \%$ and 20\% below the screening goals of "Healthy People 2010" [14]. The reasons for lack of screening were unclear and the authors recommended information campaigns to address this screening deficit.

Interventions at an organizational level can be effective for vulnerable groups. A program using lay health workers to educate and navigate Mexican-American women led to an increase in Pap smear screening in this population [15]. Another similar intervention recruited female family members among Arab, African American, and Latina women to increase willingness to get screened [16].

\subsection{Challenges at the Community Level}

The community level includes factors that affect healthcare that derive from issues of race, socio-economic status, the resources of available public resources, and the "built environment". Minorities by race and ethnicity experience a disproportionate incidence of cervical cancer compared to whites. In African American women, the rate of cervical cancer escalates with age [3]. Looking at changes in disparities from 1979 to 2009, the cervical cancer incidence equalized for younger African American women compared to whites but the disparities persisted for older black women [17]. Delay in definitive therapy for cervical cancer occurs among women with lower income and educational background. Analysis of delays pointed to financial barriers, delay on the part of the doctor, and inability to navigate the healthcare system [18].

In Georgia, there were geographic differences in incidence and death rates for cancer that appeared to be directly linked to proximity to health centers and socioeconomic status [19]. The mortality to incidence ratio (MIR) is higher among black women at 0.423 compared to white women with a MIR of 0.279 [19].

Another study looking at screening among African immigrant women in Minnesota analyzed health behaviors through a survey [20]. Age and education were not associated with getting Pap smears. The most important factor was duration of living in the United States. This data suggests that unlike African American women, the barriers to Pap smear screening for immigrant women have more to do with learning the system of a new country.

Native American women reported reluctance to use health care facilities for cancer screening because of perceived discrimination [21]. Other factors of importance for these women included a high school education, unemployment, and a history of diabetes.

\subsection{Cervical Cancer Screening Disparities at the Society Level}

The societal influences of healthcare usage and outcomes include the infrastructure of healthcare, the presence of health facilities, economics, the educational system, and government policy.

The incidence of cervical cancer in the United States varies by geography and region. This partially reflects areas of deep poverty such as Appalachia, the Deep South, and the Mexican-Texan border. For example, the incidence of cervical cancer and the cancer death rate is higher among white women in Appalachia than among white women who do not live in Appalachia (9.6 and 3.1 per 100,000 and 7.7 and 2.3 per 100,000 respectively) [22]. There are disparities in medical infrastructure utilization. Follow-up of abnormal results and utilization of treatment services are significantly delayed for ethnic minorities and poor women compared to white women [23].

\section{Cervical Cancer Screening Challenges around the World}

In Malaysia, the incidence of cervical cancer is increasing [24]. However, semi-structured interviews of patients with cancer revealed that the majority of people had never heard of cancer screening tests. Analysis of the barriers to cervical cancer screening revealed a lack of public education suggesting an organizational level deficit. This was combined with a personal and community belief system that was suspicious of medical testing [24].

Cervical cancer screening rates have been increasing in Korea from 40\% in 1998 to $52.5 \%$ in 2010 . However demographic data reveal that screening is related to socioeconomic status through educational level and household income [25]. This data suggests that the main barrier to screening in Korea is at the organizational level in the social ecology model. This same pattern by socioeconomic status for cervical cancer was identified looking at cancer registry data in Iran [26]. 
In Argentina and Latin America in general, cervical cancer is the second most common cancer in women. An analysis of Pap smear screening showed an increase in screening from $51.6 \%$ in 2005 to $60.5 \%$ in 2009 [27]. However, most of the increase in Pap smears screening has been among the high-income women. An evaluation of eight provinces in Argentina revealed either a stable or an increasing inequality by income and education gradients among medium-income women. This suggests that the world economic crisis has differentially impacted the medium-income group.

In the European Union, all the countries of the EU have universal healthcare. Disparities in screening are still seen. For instance, in the United Kingdom, cervical cancer screening rates were significantly lower in women with learning disabilities [28]. This barrier is at the intrapersonal level and would require the establishment of a navigation system within the medical infrastructure to address this population a risk. In Italy, education and occupation were associated with high levels of cervical cancer screening compared to unemployed women [29].

\section{Conclusion}

The barriers to cervical cancer screening are complex and intimately linked to social, cultural, and societal forces.

\section{REFERENCES}

[1] ASCCP American Society of Colposcopy and Cervical Pathology, "Updated Consensus Guidelines for the Management of Abnormal Cervical Cancer Screening Tests, and Cancer Precursors," 2012.

http://www.asccp.org/Guidelines/Updated-Consensus-Gu idelines

[2] I. Brankovic, P. Verdonik and I. Klinge, "Applying a Gender Lens on Human Papillomavirus Infection: Cervical Cancer Screening, HPV DNA Testing, and HP Vaccination," International Journal Equity Health, Vol. 12, No. 14, 2013, pp. 1-10.

http://www.equityhealthj.com/content/12/1/14

[3] C. M. Pierce Campbell, L. J. Menezes, E. D. Paskett and A. R. Giuliano, "Prevention of Invasive Cervical Cancer in the United States: Past, Present, and Future," Cancer Epidemiology Biomarkers Prevenetion, Vol. 21, No. 9, 2012, pp. 1402-1408. http://dx.doi.org/10.1158/1055-9965.EPI-11-1158

[4] M. G. del Carmen and M. Avila-Wallace, "Effect of Health Care Disparities on Screening," Clinical Obstetrics and Gynecology, Vol. 56, No. 1, 2013, pp. 65-75. http://dx.doi.org/10.1097/GRF.0b013e31827af75a

[5] A. C. Kronman, K. M. Freund, T. Heeren, K. A. Beaver, M. Flynn and T. A. Battaglia, "Depression and Anxiety Diagnoses Are Not Associated with Delayed Resolution of Abnormal Mammograms and Pap Tests among Vulnerable Women," Journal of General Internal Medicine,
Vol. 27, No. 4, 2012, pp. 452-457. http://dx.doi.org/10.1007/s11606-011-1920-5

[6] A. Aggarwal, A. Pandurangi and W. Smith, "Disparities in Breast and Cervical Cancer Screening in Women with Mental Illness: A Systematic Literature Review," American Journal Preventive Medicine, Vol. 44, No. 4, 2013, pp. 392-398. http://dx.doi.org/10.1016/j.amepre.2012.12.006

[7] L. M. Niccolai, C. Russ, P. J. Julian, S. Hariri, J. Sinard, J. I. Meek, V. McBride, L. E. Markowitz, E. R. Unger, J. L, Hadler and L. E. Sosa. "Individual and Geographic Disparities in Human Papillomavirus Types 16/18 in HighGrade Cervical Lesions: Associations with Race, Ethnicity, and Poverty," Cancer, Vol. 119, No. 16, 2013, pp. 3052-3058. http://dx.doi.org/10.1002/cncr.28038

[8] S. Tu. Jackson, S. L. Y. Yasui, M. Deschamps, T. G. Hislop and V. M. Taylor, "Cancer Preventive Screening: Across-Border Comparison of United States and Canadien Chinese Women,” Preventive Medicine, Vol. 41, No. 1, 2005, pp. 36-46. http://dx.doi.org/10.1016/j.ypmed.2005.01.005

[9] S. C. Chang, J. S. Woo, V. Yau, B. B. Gorzalka and L. A. Brotto, "Cervical Cancer Screening and Chinese Women: Insights from Focus Groups,” Frontiers in Psycholology, Vol. 4, No. 48, 2013 。 http://dx.doi.org/10.3389/fpsyg.2013.00048

[10] A. M. Roncancio, K. K. Ward and M. E. Fernandez, "Understanding Cervical Cancer Screening Intentions among Latinas Using an Expanded Theory of Planned Behavior Model," Behavioral Medicine, Vol. 39, No. 3, 2013, pp. 66-72. http://dx.doi.org/10.1080/08964289.2013.799452

[11] B. Elias, E. V. Kliewer, M. Hall, A. A. Demers, D. Turner, P. Martens, S. P. Hong, L. Hart, C. Chartrand and G. Munro, “The Burden of Cancer Risk in Canada's Indigenous Population: A Comparative Study of Known Risks in a Canadian Region,” International Journal of General Medicine, Vol. 4, No. 4, 2011, pp. 699-709. http://dx.doi.org/10.2147/IJGM.S24292

[12] J. D. Bellinger, H. M. Brandt, J. W. Hardin, S. A. Bynum, P. A. Sharpe and D. Jackson, "The Role of Family History of Cancer on Cervical Cancer Screening Behavior in a Population-Based Survey of Women in the Southeastern United States,” Women's Health Issues, Vol. 23, No. 4, 2013, pp. e197-204.

http://dx.doi.org/10.1016/j.whi.2013.03.003

[13] X. Niu, L. M. Roche, K. S. Pawlish and K. A. Henry, "Cancer Survival Disparities by Health Insurance Status," Cancer Medicine, Vol. 2, No. 3, 2013, pp. 403-411. http://dx.doi.org/10.1002/cam4.84

[14] C. R. Clark, N. Baril, A. Hall, M. Kunicki, N. Johnson, J. Soukup, S. Lipsitz and J. Bigby, "Case Management Intervention in Cervical Cancer Prevention: The Boston REACH Coalition Women's Health Demonstration Project," Progress in Community Health Partnerships, Vol. 5, No. 3, 2011, pp. 235-247. http://dx.doi.org/10.1353/cpr.2011.0034

[15] T. L. Byrd, K. M. Wilson, J. L. Smith, G. Coronado, S. W. Vernon, M. E. Fernandez-Esquer, B. Thompson, M. Ortiz, D. Lairson and M. E. Fernandez, "AMIGAS: A Multicity, 
Multicomponent Cervical Cancer Prevention Trial among Mexican American Women,” Cancer, Vol. 119, No. 7, 2013, pp. 1365-1372. http://dx.doi.org/10.1002/cncr.27926

[16] K. P. Williams, L. Roman, C. I. Meghea, L. Penner, A. Hammad, J. Gardiner and S. M. Kin Keeper, "Design and Baseline Characteristics of a Community-Based Randomized Controlled Trial Promoting Cancer Screening in Black, Latina, and Arab Women,” Contemporary Clinical Trials, Vol. 34, No. 2, 2013, pp. 312-319. http://dx.doi.org/10.1016/j.cct.2012.12.005

[17] E. P. Simard, D. Naishadham, D. Saslow and A. Jemal, "Age-Specific Trends in Black-White Disparities in Cervical Cancer Incidence in the United States: 1975-2009,” Gynecologic Oncology, Vol. 127, No. 3, 2012, pp. 611615. http://dx.doi.org/10.1016/j.ygyno.2012.08.021

[18] K. Ashing-Giwa and M. Rosales, "Evaluation of Therapeutic Care Delay among Latina- and European American Cervical Cancer Survivors,” Gynecologic Oncology, Vol. 128, No. 2, 2013, pp. 160-165.

http://dx.doi.org/10.1016/j.ygyno.2012.11.015

[19] S. E. Wagner, D. M. Hurley, J. R. Hébert, C. McNamara, A. R. Bayakly and J. E. Vena, "Cancer Mortality-to-Incidence Ratios in Georgia: Describing Racial Cancer Disparities and Potential Geographic Determinants,” Cancer, Vol. 118, No. 16, 2012, pp. 4032-4045.

[20] N. Harcourt, R. G. Ghebre, G. L. Whembolua, Y. Zhang, S. Warfa Osman and K. S. Okuyemi, "Factors Associated with Breast and Cervical Cancer Screening Behavior Among African Immigrant Women in Minnesota,” Journal of Immigrant and Minority Health. http://dx.doi.org/10.1007/s10903-012-9766-4

[21] K. L. Gonzales, A. K. Harding, W. E. Lambert, R. Fu and W. G. Henderson, "Perceived Experiences of Discrimination in Health Care: A Barrier for Cancer Screening among American Indian Women with Type 2 Diabetes,” Women's Health Issues, Vol. 23, No. 1, 2013, pp. e61-67. http://dx.doi.org/10.1016/j.whi.2012.10.004

[22] K. J. Bennett, C. Pumkam, J. D. Bellinger and J. C. Probst, "Cancer Screening Delivery in Persistent Poverty Rural Counties,” Journal Primary Care Community Health, Vol. 2, No. 4, 2011, pp. 240-249. http://dx.doi.org/10.1177/2150131911406123
[23] C. M. Chang, Y. C. Su, N. S. Lai, K. Y. Huang, S. H. Chien, Y. H. Chang, W. C. Lian, T. W. Hsu and C. C. Lee, "The Combined Effect of Individual and Neighborhood Socioeconomic Status on Cancer Survival Rates," PLoS One, Vol. 7, No. 8, 2012, Article ID: e44325. http://dx.doi.org/10.1371/journal.pone.0044325

[24] M. Farooqui, M. A. Hassali, A. Knight, A. A. Shafie, M. A. Farooqui, F. Saleem, N. U. Haq and H. Aljadhey, “A Qualitative Exploration of Malaysian Patients' Perceptions of Cancer Screening,” BMC Public Health, Vol. 13 No. 48, 2013, pp. 1-7. http://www.ncbi.nlm.nih.gov/pmc/articles/PMC3564681/

[25] M. Lee, E. C. Park, H. S. Chang, J. A. Kwon, K. B. Yoo and T. H. Kim, "Socioeconomic Disparity in Cervical Cancer Screening among Korean Women: 1998-2010," BMC Public Health, Vol. 13, No. 553, 2013, pp. 1-8. http://www.ncbi.nlm.nih.gov/pmc/articles/PMC3682861/ pdf/1471-2458-13-553.pdf

[26] M. Rohani-Rasaf, M. Moradi-Lakeh, R. Ramezani and M. Asadi-Lari, "Measuring Socioeconomic Disparities in Cancer Incidence in Tehran, 2008,” Asian Pacific Journal of Cancer Prevention, Vol. 13, No. 6, 2012, pp. 29552960. http://dx.doi.org/10.7314/APJCP.2012.13.6.2955

[27] F. G. De Maio, B. Linetzky and D. Ferrante, "Changes in the Social Gradients for Pap Smears and Mammograms in Argentina: Evidence from the 2005 and 2009 National Risk Factor Surveys,” Public Health, Vol. 126, No. 10, 2012, pp. 821-826. http://dx.doi.org/10.1016/j.puhe.2012.05.011

[28] D. P. Osborn, L. Horsfall, A. Hassiotis, I. Petersen, K. Walters and I. Nazareth, “Access to Cancer Screening in People with Learning Disabilities in the UK: Cohort Study in the Health Improvement Network, a Primary Care Research Database,” PLoS One, Vol. 7, No. 8, 2012, Article ID: e43841. http://dx.doi.org/10.1371/journal.pone.0043841

[29] G. Damiani, B. Federico, D. Basso, A. Ronconi, C. B. Bianchi, G. M. Anzellotti, G. Nasi, F. Sassi and W. Ricciardi, "Socioeconomic Disparities in the Uptake of Breast and Cervical Cancer Screening in Italy: A Cross Sectional Study,” BMC Public Health, Vol. 12, No. 99, 2012. 